\title{
Generalized Binomial Trees
}

\author{
by \\ Jens Carsten Jackwerth*
}

First draft: August 19, 1996

This version: May 12, 1997

\begin{abstract}
We consider the problem of consistently pricing new options given the prices of related options on the same stock. The Black-Scholes formula and standard binomial trees can only accommodate one related European option which then effectively specifies the volatility parameter. Implied binomial trees can accommodate only related European options with the same time-to-expiration. The generalized binomial trees introduced here can accommodate any kind of related options (European, American, or exotic) with different times-to-expiration.
\end{abstract}

\footnotetext{
* Jens Carsten Jackwerth is a post-doctoral visiting scholar at the Haas School of Business, University of California at Berkeley. For helpful discussions, I would like to thank Mark Rubinstein.
} 


\section{Generalized Binomial Trees}

In order to motivate the method of generalized binomial trees for option pricing, let us consider a rather common problem. You are asked to price a new equity option and you are also given the prices of related options on the same stock. If you believe in efficient markets, then you want to price your new option in a consistent manner with the given prices of the related options. We will introduce additional related options one at a time and see that our common models can only handle rather specific cases. Generalized binomial trees enable us to incorporate price information on any kind of related options (European, American, or exotic) with different times-to-expiration.

\section{Standard Binomial Trees}

Say you are working an options desk and a client asks you to price a European call with striking price 1 expiring in two years. Fortunately, you have some additional information. The stock is at 1, there are no dividends, and the interest rate is zero. Easy enough, after you estimate the volatility of the stock you can price the option with the Black-Scholes formula or a standard binomial tree. But in real life, you often know about the prices of other related options traded on the same stock. Here, you are aware of a European call with striking price 1 and expiring in three years which trades at .4815 . Of course, you use the Black-Scholes formula to find the implied volatility of your given call and then price your client's call. Or equivalently, you can work it out in a standard binomial tree (Cox, Ross, and Rubinstein (1979)) with, say, three timesteps. After some search you establish the implied volatility of your given call at .6931 . The up-move $u$ for the stock price is therefore given by $\mathrm{e}^{6931 \sqrt{ } 1}=2$ and your tree for the stock itself looks as follows: 


\section{Exhibit 1:}

Stock price in the standard binomial tree.

1
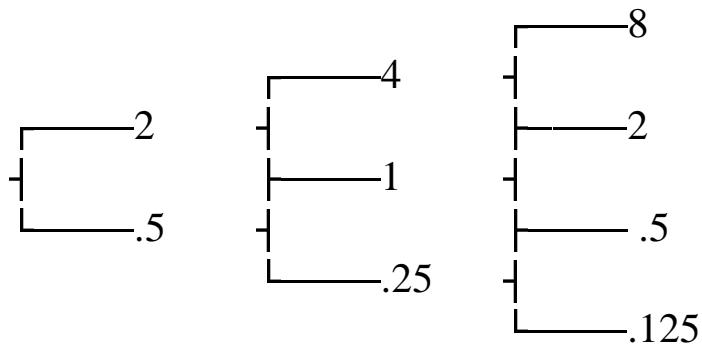

You evaluate the transition probability $\mathrm{p}=((\mathrm{r} / \delta)-\mathrm{d}) /(\mathrm{u}-\mathrm{d})=((1 / 1)-.5) /(1.5-.5)=.3333$ where $\mathrm{r}$ is 1 plus the interest rate per step, $\delta$ is 1 plus the dividend yield per step, $\mathrm{u}$ is the up-move, and $\mathrm{d}$ is the down-move. Next, you use the recursive relation $\mathrm{C}=\left[\mathrm{p} \mathrm{C}_{\mathrm{up}}+(1-\mathrm{p}) \mathrm{C}_{\mathrm{down}}\right] / \mathrm{r}$. You then evaluate your given call as:

\section{Exhibit 2:}

Your given call in the standard binomial tree.

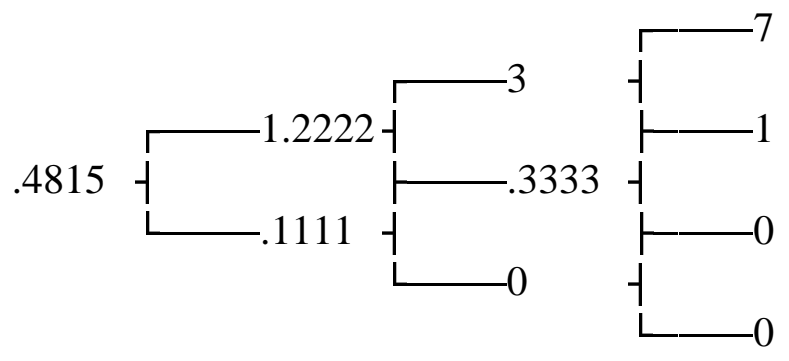

You see that you priced your given call correctly. Next, you evaluate your client's call: 


\section{Exhibit 3:}

\section{Your client's call in the standard binomial tree.}

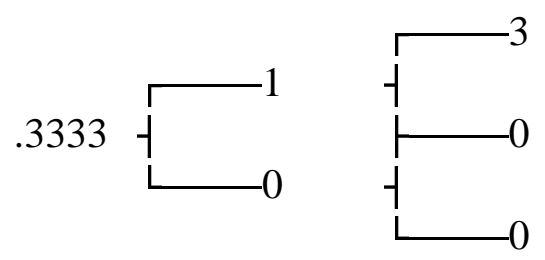

Your result is .3333 and you think your problem is solved.

\section{Implied Binomial Trees}

However, at this point your desk manager has great news. Judy found out that there is also a European put traded with striking price .95 and three years to expiration. Its value is .445 and she asks you what the value of your client's call is, given this additional information. Evaluating the put on your old tree gives you a value of .4444 and you realize that you are looking at part of a volatility smile. This means that the implied volatilities of options with different striking prices (but the same time-to-expiration) are not identical. Therefore, the standard binomial tree does not work any longer and the same goes for the Black-Scholes formula. But you don't despair yet since you remember that you can build an implied binomial tree (Rubinstein (1994)) which you can fit to your and Judy's given options since they expire at the same time. But before you can build the implied binomial tree, you have to find a set of risk-neutral (nodal) probabilities which price the two given options, the stock itself, and which sum to 1: 


$\begin{array}{llllll}\left(\mathrm{P}_{0}{ }^{\text {nodal }} 0\right. & +\mathrm{P}_{1}{ }^{\text {nodal }} 0 & +\mathrm{P}_{2}{ }^{\text {nodal }} 1 & +\mathrm{P}_{3}{ }^{\text {nodal }} 7 & ) / \mathrm{r}^{3} & =.4815 \\ \left(\mathrm{P}_{0}{ }^{\text {nodal }} .825\right. & +\mathrm{P}_{1}{ }^{\text {nodal }} .45 & +\mathrm{P}_{2}{ }^{\text {nodal }} 0 & +\mathrm{P}_{3}{ }^{\text {nodal }} 0 & ) / \mathrm{r}^{3} & =.445 \\ \left(\mathrm{P}_{0}^{\text {nodal }} .125\right. & +\mathrm{P}_{1}{ }^{\text {nodal }} .5 & +\mathrm{P}_{2}{ }^{\text {nodal }} 2 & +\mathrm{P}_{3}{ }^{\text {nodal }} 8 & ) /(\mathrm{r} / \delta)^{3} & =1 \\ \left(\mathrm{P}^{\text {nodal }} 1\right. & +\mathrm{P}_{1}{ }^{\text {nodal }} 1 & +\mathrm{P}_{2}{ }^{\text {nodal }} 1 & +\mathrm{P}_{3}{ }^{\text {nodal }} 1 & ) & =1\end{array}$

This system of equations can be solved for the desired (nodal) probabilities $\mathrm{P}_{0}{ }^{\text {nodal }}=.3111, \mathrm{P}_{1}{ }^{\text {nodal }}=$ $.4185, \mathrm{P}_{2}^{\text {nodal }}=.2352$, and $\mathrm{P}_{3}^{\text {nodal }}=.0352$ associated with stock prices of $.125, .5,2$, and 8 , respectively. If you had been faced with more potential stock prices than equations, as is normally the case, you would have had to resort to one of the more general methods to derive risk-neutral probabilities given your set of stock prices in year three (e.g. Shimko (1993), Jackwerth and Rubinstein (1996)). These methods effectively interpolate and extrapolate the existing option prices to find hypothetical option prices at striking prices corresponding to all potential stock prices. You can then infer the nodal probabilities from such a set of options prices by differentiating twice with respect to the striking price and multiplying the result by $\mathrm{r}^{3}$ (Breeden and Litzenberger (1978)). You can now unravel the implied stock price tree: 


\section{Exhibit 4:}

\section{Stock price in the implied binomial tree.}

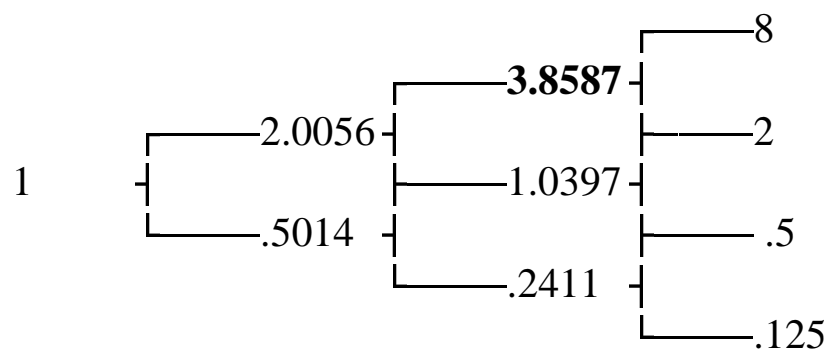

To do so, you calculate path probabilities at the end of the tree based on your nodal probabilities. The nodal probabilities are the total probability of reaching a given node in a tree. However, in a binomial tree there are several paths to reach any such given node. The exact number of paths is the binomial coefficient $\left(\begin{array}{l}i \\ j\end{array}\right)=\frac{i !}{j !(j-i) !}$ where $\mathrm{i}=0, \ldots, \mathrm{n}$ is the step of the tree and $\mathrm{j}=0, \ldots, \mathrm{i}$ is the level within that step. An implied binomial tree assumes that each path is equally likely to be taken. You therefore calculate the path probabilities by dividing each nodal probability by the number of paths leading up to that node. The nodal probabilities are $\mathrm{P}_{0}^{\text {nodal }}=.3111, \mathrm{P}_{1}^{\text {nodal }}=$ $.4185, \mathrm{P}_{2}{ }^{\text {nodal }}=.2352$, and $\mathrm{P}_{3}{ }^{\text {nodal }}=.0352$. After dividing by $1,3,3$, and 1 , you find that the path probabilities are $\mathrm{P}_{0}{ }^{\text {path }}=.3111, \mathrm{P}_{1}{ }^{\text {path }}=.1395, \mathrm{P}_{2}{ }^{\text {path }}=.0784$, and $\mathrm{P}_{3}{ }^{\text {path }}=.0352$ for the stock levels of $.125, .5,2$, and 8 , respectively.

Last, you derive the transition probabilities $\mathrm{p}$ for the recursion which will now be different for each node. Schematically, you are concerned with finding the preceding node given the two later nodes: 


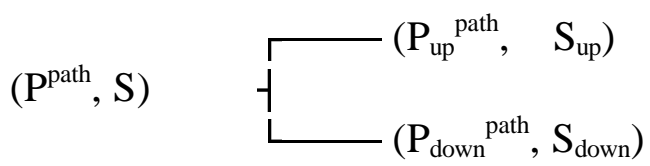

First, you calculate $\mathrm{P}^{\text {path }}=\mathrm{P}_{\text {up }}^{\text {path }}+\mathrm{P}_{\text {down }}{ }^{\text {path }}$.

Second, you calculate the transition probability as $\mathrm{p}=\mathrm{P}_{\mathrm{up}}^{\text {path }} / \mathrm{P}^{\text {path }}=\mathrm{P}_{\text {up }}^{\text {path }} /\left(\mathrm{P}_{\text {up }}^{\text {path }}+\mathrm{P}_{\text {down }}^{\text {path }}\right)$.

Third, you calculate the stock price $S=\left[p S_{\text {up }}+(1-p) S_{\text {down }}\right] /(r / \delta)$.

For the highlighted node in exhibit 4 with the stock price 3.8587, the calculations are $\mathrm{p}=.0352$ / $(.0352+.0784)=.3098$. The stock price is thus $S=[.30988+(1-.3098) 2] /(\mathrm{r} / \delta)=3.8587$.

You now evaluate your given call by using the same transition probabilities $\mathrm{p}$ as above and the recursion $\mathrm{C}=\left[\mathrm{p} \mathrm{C}_{\mathrm{up}}+(1-\mathrm{p}) \mathrm{C}_{\mathrm{down}}\right] / \mathrm{r}$ as:

\section{Exhibit 5:}

Your given call in the implied binomial tree.

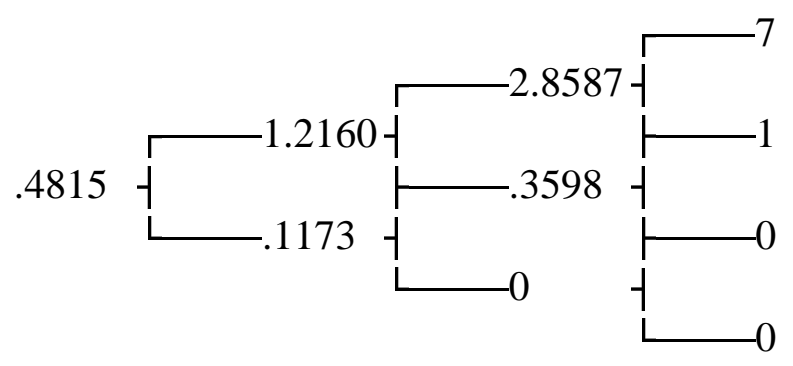

You see that you priced your given call correctly. You also check for Judy's given put which you evaluate as: 


\section{Exhibit 6:}

Judy's given put in the implied binomial tree.

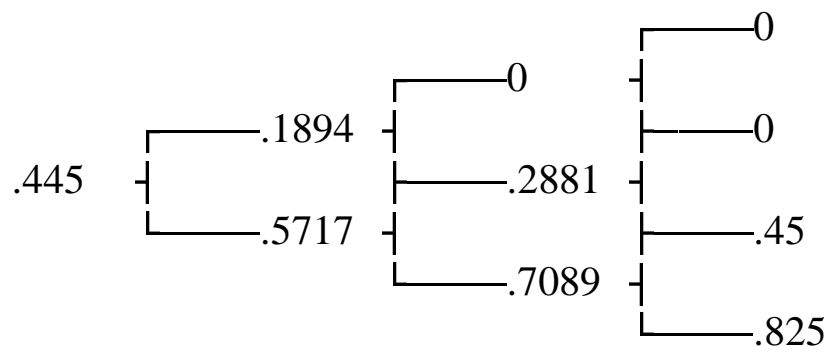

After you realize that Judy's given put is also priced correctly, you go on to evaluate your client's call:

\section{Exhibit 7:}

Your client's call in the implied binomial tree.

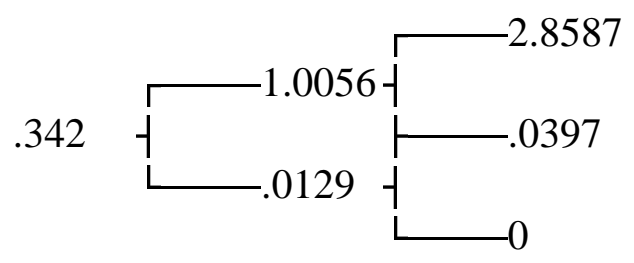

Your result is .342 and again you think your problem is solved. 


\section{Generalized Binomial Trees}

But as luck would have it, the situation changes again, and the head of derivatives finds even another option. Tom informs you that there is also another European put traded with striking price 1.05 and two years to expiration. Its value is .4029 and he asks you what your client's call is worth given the prices of all 3 given options. The value of Tom's given put based on the implied binomial tree above is only .369 and you cannot use the implied binomial tree approach any longer. So you are wondering about a more general framework. Ideally, it would preserve the simplicity of binomial trees while allowing the tree to fit options with different implied volatilities and different times-to-expiration.

You go to the library and peruse the relevant literature. Derman and Kani (1994) and Dupire (1994) suggest related implied trees which are calibrated to a large set of option prices. For each node, they need a corresponding option price with striking price equal to the nodal stock price and expiring at the time associated with that node. Since they are faced with far fewer given option prices than required, they need to interpolate and extrapolate from given option prices. Their trees are rather sensitive to the interpolation and extrapolation method and require adjustments to avoid arbitrage violations. Also, Lagnado and Osher (1996) suggest a method of calibrating a finite difference grid to options prices. Their method seems to be rather computationally intensive. In comparison, the implied binomial tree you used so far is always arbitrage-free, easy to understand, and fast to compute. At this point you wonder if it is not possible to generalize your old implied binomial tree. A natural candidate for generalization would be the assumption that all paths leading to the same node are equally likely to be taken. That assumption gives the implied 
binomial tree much structure but at the same time limits its flexibility to fit additional options which expire earlier.

Now it is time for you to retrace your steps and you look at the nodal probabilities, that is the total risk-neutral probability that you reach some node. For the standard binomial tree, the transition probabilities were .3333 throughout the tree. The nodal probabilities are therefore:

\section{Exhibit 8:}

\section{Nodal probabilities in the standard binomial tree.}

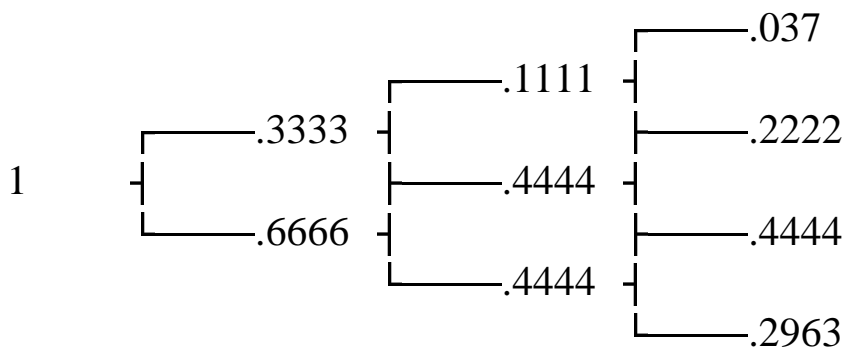

You ask yourself how much of the uppermost ending probability (.037) ends up as part of the probability at the preceding node? Well, all of it since it has no other way to go. That means that $.1111-.037=.0741$ must have come from the second uppermost ending node. In relative terms, $1 / 3$ of $.2222(=.0741)$ went up and that leaves $2 / 3$ of $.2222(=.1481)$ to go down into the .4444 probability at the center node of step 2 . The remaining $.4444-.1481=.2963$ must have come from the third uppermost ending node. In relative terms, $2 / 3$ of $.4444(=.2963)$ went up and that leaves $1 / 3$ of $.4444(=.1481)$ to go down. Finally, all of the fourth uppermost ending node (the bottom node) must have gone up since it had no way to go down. Amazingly, this pattern holds 
for the whole tree at all steps: If you number the steps $\mathrm{i}=0,1, \ldots, \mathrm{n}$ and the nodes in each step $\mathrm{j}$ $=0,1, \ldots, i$, then the portion of nodal probability going down will be $w(j / i)=j / i$ and the portion of probability going up will be $1-\mathrm{w}(\mathrm{j} / \mathrm{i})$. You can depict these down portions nicely as a linear function across different $\mathrm{j} / \mathrm{i}$ ratios in the following graph:

\section{Exhibit 9:}

The weight function in the standard and implied binomial trees.

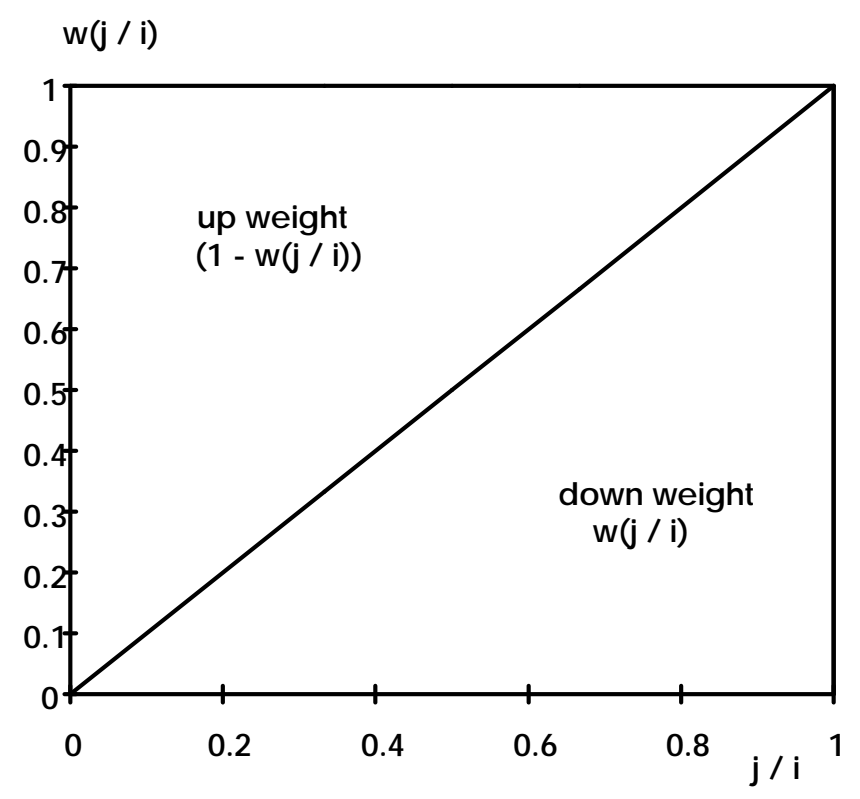

Effectively, you can summarize the entire stock process through this weight function. A standard binomial tree is then completely described by an approximately lognormal ending probability distribution and the above linear weight function. Also, it turns out that you can completely describe an implied binomial tree by an arbitrary ending probability distribution and the same linear weight function as in the standard binomial tree. 
So far you have not gained much in terms of generalization but some insight into standard and implied binomial trees. But you see a way to put this insight to good use. The standard and implied binomial trees are expressed in terms of path probabilities. You can now use the above weight function to express them in terms of nodal probabilities. You would obtain the same tree but finally you could hopefully choose more general weight functions which are not linear. This is exactly how you proceed.

Now, you work out how to express the standard and implied trees in terms of nodal probabilities. Schematically, you are concerned with finding the preceding node given the two later nodes, but now in terms of nodal probabilities. In addition, you have to keep track of where you are in the tree in terms of steps and levels since the weights depend on the location of the node in the tree.

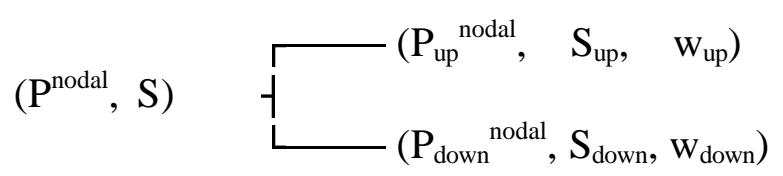

After working out the detailed proofs in the appendix, you find the following three steps.

First, you calculate $\mathrm{P}^{\text {nodal }}=\mathrm{w}_{\text {up }} \mathrm{P}_{\text {up }}^{\text {nodal }}+\left(1-\mathrm{w}_{\text {down }}\right) \mathrm{P}_{\text {down }}^{\text {nodal }}$. Here you note that the weights recursively break up the nodal probabilities and reassemble them at the preceding step. The cumulative probability is preserved at 1 at every step.

Second, you calculate the transition probability as $\mathrm{p}=\mathrm{w}_{\mathrm{up}} \mathrm{P}_{\mathrm{up}}^{\text {nodal }} / \mathrm{P}^{\text {nodal }}$. Here you note that, as long as the weights are between 0 and 1 , the transition probability $\mathrm{p}$ will also be between 0 and 1 . That means there cannot be any arbitrage violations in a generalized binomial tree with an arbitrary weight function. 
Third, you calculate the stock price $S=\left[p S_{\text {up }}+(1-p) S_{\text {down }}\right] /(r / \delta)$. Here you note that you can rewrite the stock price formula as $\mathrm{S} \mathrm{P}^{\text {nodal }}=\left[\mathrm{w}_{\mathrm{up}} \mathrm{P}_{\mathrm{up}}^{\text {nodal }} \mathrm{S}_{\mathrm{up}}+\left(1-\mathrm{w}_{\text {down }}\right) \mathrm{P}_{\text {down }}{ }^{\text {nodal }} \mathrm{S}_{\text {down }}\right] /(\mathrm{r} / \delta)$. The weights also recursively break up the products of nodal probabilities and stock prices and reassemble them at the preceding step. The risk-neutral present value of the stock is thus preserved at every step.

These are the equivalent formulas to construct standard and implied binomial trees expressed in terms of nodal probabilities.

Next, you consider more general weight functions. In order to add one degree of freedom, you can choose one weight, say $\mathrm{w}(.5)$, arbitrarily. You also know that $\mathrm{w}(0)=0$ since at the bottom node you cannot move down any further and $\mathrm{w}(1)=1$ since at the top node you must move down. Finally, you draw a piecewise linear function through those points. The weight function for w(.5) $=.75$ looks as follows: 


\section{Exhibit 10:}

\section{Linear and generalized weight functions.}

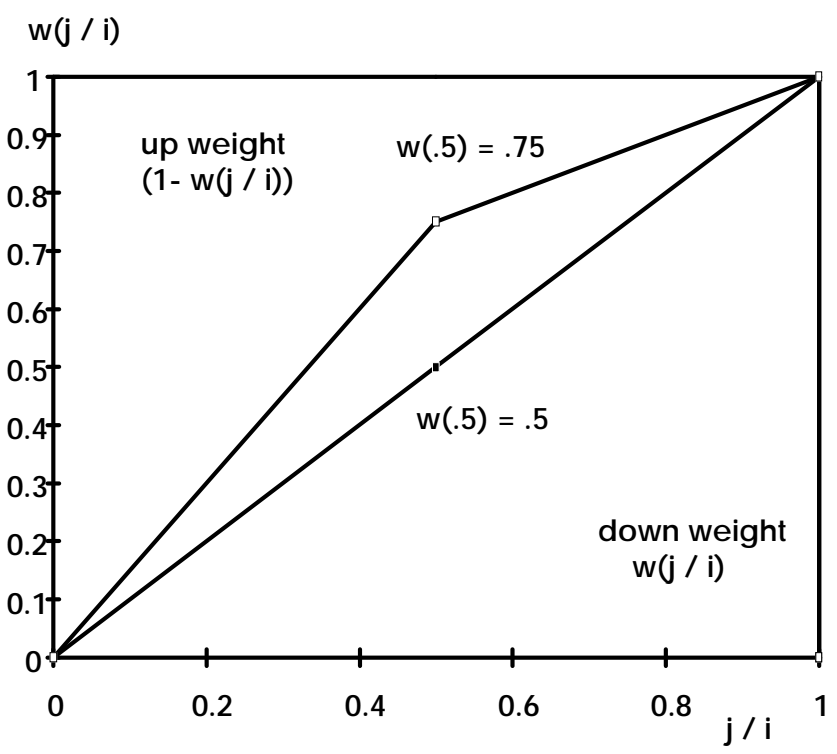

Looking at the above concave weight function with $\mathrm{w}(.5)=.75$, you wonder what this weight function does to the path probabilities. In an implied binomial tree, any path leading from today's stock price to some given node at the end would be taken with equal probability. With the concave weight function you figure that a path looping down first and then coming back up is more likely to be taken than a path looping up and then coming back down. The reverse holds of course for convex weight functions. A quick check based on the European index options on the S\&P500 in the post-crash period (1987-1994) shows you that concave weight functions explain the observed option prices better than either linear or convex weight functions.

Each weight function describes a different tree and you use this feature to fit the prices of additional related options. In particular, you can now vary $w(.5)$ from 0 to 1 and find the value for 
$\mathrm{w}(.5)$ which prices Tom's given option correctly. After some optimization, you find that $\mathrm{w}(.5)$ should be .75 . Now you construct the generalized binomial tree given this weight function. You can unravel the implied stock price tree as:

\section{Exhibit 11:}

\section{Stock price in the generalized binomial tree.}

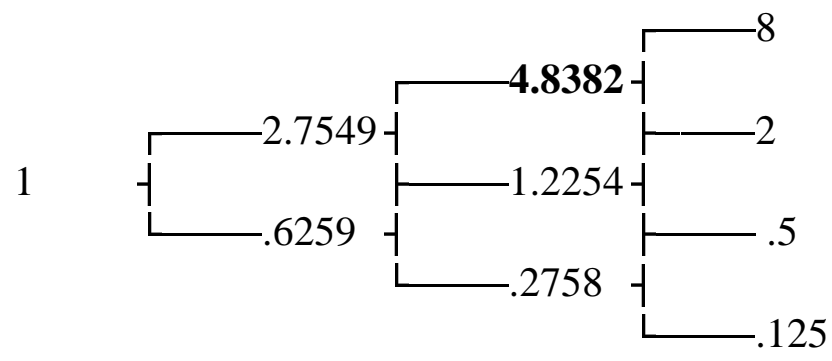

To do so, you need the ending nodal probabilities again which did not change from the implied binomial tree. That also insures that your and Judy's given options will be priced correctly. The nodal probabilities are $\mathrm{P}_{0}{ }^{\text {nodal }}=.3111, \mathrm{P}_{1}{ }^{\text {nodal }}=.4185, \mathrm{P}_{2}{ }^{\text {nodal }}=.2352$, and $\mathrm{P}_{3}{ }^{\text {nodal }}=.0352$. Next you need the weights at the ending nodes. Given the new kinked weight function, the weights are $\mathrm{w}(0 / 3)=0, \mathrm{w}(1 / 3)=.5, \mathrm{w}(2 / 3)=.8333$, and $\mathrm{w}(3 / 3)=1$ for the stock prices of $.125, .5,2$, and 8, respectively. First, you focus on the highlighted node in exhibit 11 with the stock price 4.8382 and calculate $\mathrm{P}^{\text {nodal }}=\mathrm{w}_{\text {up }} \mathrm{P}_{\text {up }}^{\text {nodal }}+\left(1-\mathrm{w}_{\text {down }}\right) \mathrm{P}_{\text {down }}^{\text {nodal }}=1.0352+(1-.8333) .2352=$ .0744. Second, you calculate the transition probability as $\mathrm{p}=\mathrm{w}_{\mathrm{up}} \mathrm{P}_{\text {up }}^{\text {nodal }} / \mathrm{P}^{\text {nodal }}=1.0352 / .0744$ $=.4730$. Third, you calculate the stock price $S=\left[p S_{\text {up }}+(1-p) S_{\text {down }}\right] /(r / \delta)=[.47308+(1-$ $.4730) 2] /(\mathrm{r} / \delta)=4.8382$. 
You now evaluate your given call by using the same transition probabilities $\mathrm{p}$ as above and the recursion $\mathrm{C}=\left[\mathrm{p}_{\mathrm{up}}+(1-\mathrm{p}) \mathrm{C}_{\mathrm{down}}\right] / \mathrm{r}$ as:

\section{Exhibit 12:}

Your given call in the generalized binomial tree.

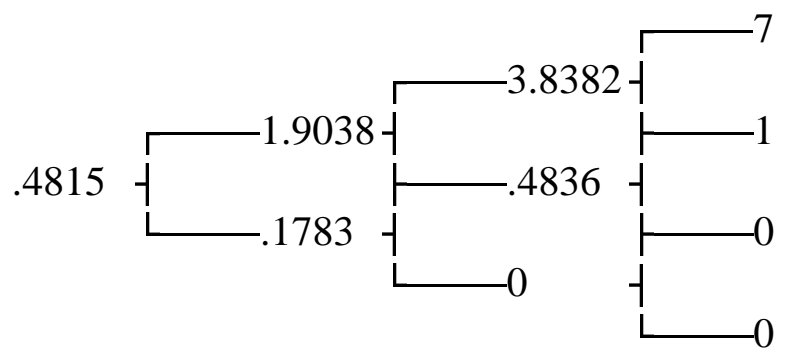

You see that you priced your given call correctly. You also check for Judy's given put which you evaluate as:

\section{Exhibit 13:}

Judy's given put in the generalized binomial tree.

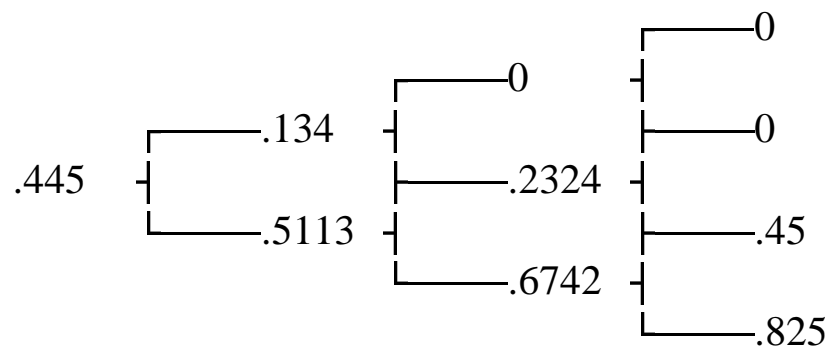

After you realize that Judy's given put is also priced correctly, you still have to check Tom's given put: 


\section{Exhibit 14:}

Tom's given put in the generalized binomial tree.

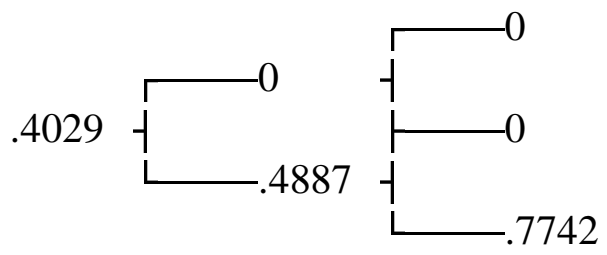

Tom's put is also priced correctly and you finally go on to evaluate your client's call:

\section{Exhibit 15:}

\section{Your client's call in the generalized binomial tree.}

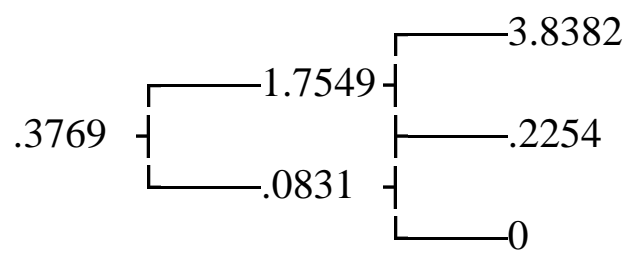

Your result is .3769 and again you think your problem is solved. You are just about to give your client a ring before you call it a night when you see the managing director heading towards your desk. Throughout the day you already acquired some fame around the cubicles for being able to fit these given options, and you are worried that Helen is going to test that in some way. And so it is. Helen found out that yours, Judy's, and Tom's given options were all misquoted as European options while they are really American options. Moreover, the interest rate and dividend yield are both predicted to be .01 per year for the next three years. Helen asks you what the client's call is 
worth given this new information. You point out that it probably does not matter since the interest rate and dividend yield are so low, but she insists, ever so gently, on a more formal approach. After all, the question of how to value an option given the prices of related American options is of general interest.

After you sit down again, you start assessing how much information you really have: three given options which have to be priced correctly, the stock itself which has to be priced correctly, and the ending probabilities which have to sum to one. That makes five pieces of information which need to be matched by five degrees of freedom. Next you look at your generalized tree. That tree is completely specified by the ending probability distribution and the weight function. By picking the four ending probabilities you could match four pieces of information. And for the last piece of information you could choose the weight $\mathrm{w}(.5)$ again. The necessary equations look rather messy, and you resort to an optimization method.

First, you use the set of nodal probabilities and the weight function with $w(.5)=.75$ from above. Then you construct the tree with interest return $r=1.01$, dividend yield $\delta=1.01$, and for pricing the options you have to check for the early exercise condition in your new recursion $\mathrm{C}=\max \{\mathrm{S}$ $\mathrm{K},\left[\mathrm{p} \mathrm{C}_{\mathrm{up}}+(1-\mathrm{p}) \mathrm{C}_{\mathrm{down}}\right] / \mathrm{r}$ \} where $\mathrm{K}$ is the striking price. Yours, Judy's, and Tom's given options are now somewhat underpriced by $.0142, .0131$, and .008 , respectively, because of the discounting at an interest rate of .01 per year. The stock price is still correct at 1 and the probabilities sum to one, too. Next you need a measure for the misfit of your model and you use a simple squared error measure in your optimization: 
Minimize $\left\{(.4815 \text { - your given option's price based on the model })^{2}+(.445\right.$ - Judy's given option's price based on the model $)^{2}+(.4029 \text { - Tom's given option's price based on the model })^{2}+(1-$ the stock price based on the model $\left.)^{2}+(1 \text { - the sum of ending nodal probabilities })^{2}\right\}$ by varying the ending nodal probabilities and the weight $\mathrm{w}(.5)$ under the constraints that the ending nodal probabilities are non-negative and that the weight $\mathrm{w}(.5)$ is between 0 and 1 .

You briefly contemplate about writing an optimization code based on the Polak-Ribiere algorithm from scratch, but after checking your watch you settle on using a standard non-linear optimization package. It soon returns your final results as $\mathrm{w}(.5)=.731, \mathrm{P}_{0}{ }^{\text {nodal }}=.3181, \mathrm{P}_{1}{ }^{\text {nodal }}=.4356, \mathrm{P}_{2}{ }^{\text {nodal }}=$ .2047 , and $\mathrm{P}_{3}{ }^{\text {nodal }}=.0416$. You can now unravel the stock price tree as:

\section{Exhibit 16:}

\section{Stock price in the generalized binomial tree with American options.}

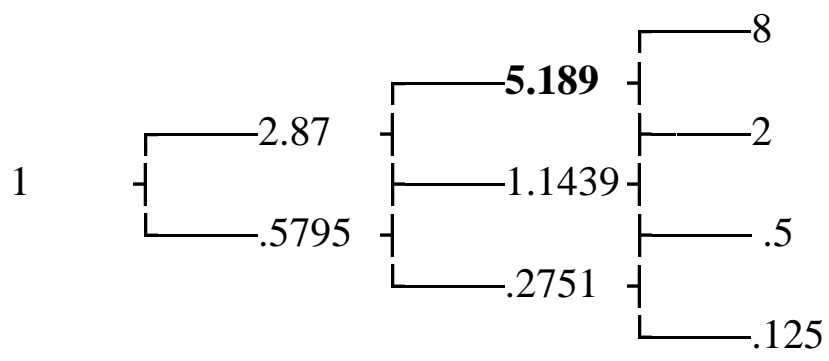

To do so, you follow the method for the generalized binomial tree but you use the optimal ending nodal probabilities and weights at the ending nodes based on the new optimal kinked weight function with $\mathrm{w}(.5)=.731$. First, you focus on the highlighted node in exhibit 16 with the stock 
price 5.189 and calculate $\mathrm{P}^{\text {nodal }}=\mathrm{w}_{\mathrm{up}} \mathrm{P}_{\mathrm{up}}^{\text {nodal }}+\left(1-\mathrm{w}_{\text {down }}\right) \mathrm{P}_{\text {down }}^{\text {nodal }}=1.0416+(1-.8207) .2047=$ .0783. Second, you calculate the transition probability as $\mathrm{p}=\mathrm{w}_{\mathrm{up}} \mathrm{P}_{\text {up }}^{\text {nodal }} / \mathrm{P}^{\text {nodal }}=1.0416 / .0783$ $=.5315$. Third, you calculate the stock price $S=\left[p S_{\text {up }}+(1-p) S_{\text {down }}\right] /(\mathrm{r} / \delta)=[.53158+(1-$. $5315) 2] /(1.01 / 1.01)=5.189$.

You now evaluate your given call by using the same transition probabilities $\mathrm{p}$ as above and the augmented recursion for American options $\mathrm{C}=\max \left\{\mathrm{S}-\mathrm{K},\left[\mathrm{p} \mathrm{C}_{\mathrm{up}}+(1-\mathrm{p}) \mathrm{C}_{\mathrm{down}}\right] / \mathrm{r}\right\}$ as:

\section{Exhibit 17:}

Your given call in the generalized binomial tree with American options.

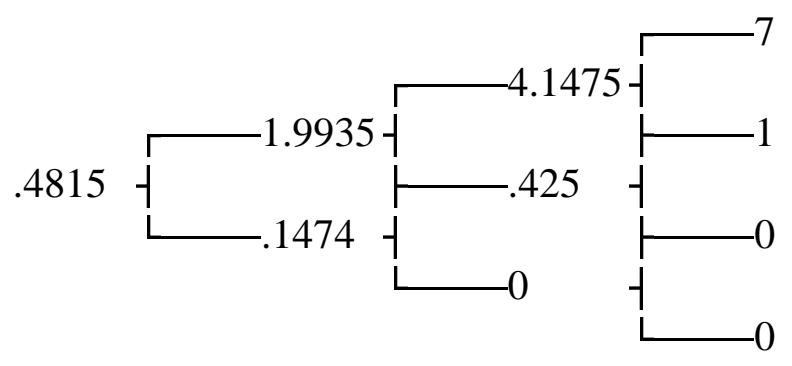

You see that you priced your given call correctly. You also check for Judy's given put which you evaluate as: 


\section{Exhibit 18:}

Judy's given put in the generalized binomial tree with American options.

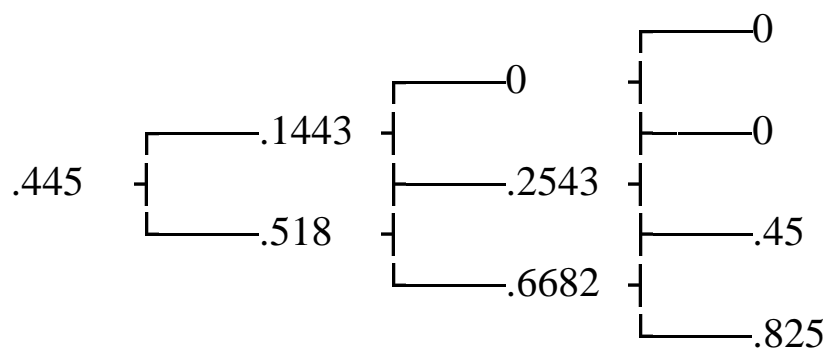

After you realize that Judy's given put is also priced correctly, you still have to check Tom's given put:

\section{Exhibit 19:}

Tom's given put in the generalized binomial tree with American options.

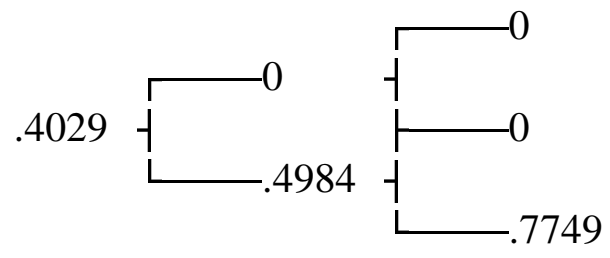

Tom's put is also priced correctly and you finally go on to evaluate your client's call: 


\section{Exhibit 20:}

Your client's given call in the generalized binomial tree with American options.

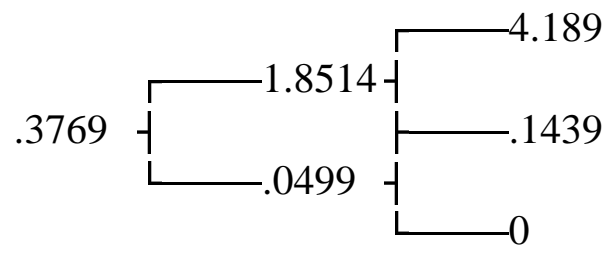

Your result is .3769 again and, indeed, the price of your client's call did not change even after reworking your tree. The reason for the small changes in the final version of the tree is that none of the American options should be exercised early and only the small change in the interest rate and the dividend yield had to be accommodated. However, you allowed for the early exercise in principle and could have handled it.

\section{Conclusion}

As you look up from your work you realize that everybody went home already. But, rather than leaving right now, you get a last cup of coffee and recap the day. In getting a systematic picture of how the different trees are all related to each other you draw the following table: 


\section{Exhibit 21:}

Relationship between standard, implied, and generalized binomial trees in terms of ending nodal probability distributions and weight functions.

\begin{tabular}{|l|l|l|}
\hline Binomial Tree & Ending Nodal Probability Distribution & Weight Function \\
\hline Standard (CRR 1979) & Lognormal & Linear \\
\hline Implied (Rubinstein 1994) & Arbitrary & Linear \\
\hline Generalized & Arbitrary & Arbitrary \\
\hline
\end{tabular}

It nicely shows you that it all starts with the standard tree which has approximately lognormal ending probabilities and a linear weight function to describe the structure of the tree. The implied binomial tree allows the ending distribution to be arbitrary but keeps the rigid linear weight function to describe the structure of the tree. The generalized binomial tree allows arbitrary ending distributions but also arbitrary weight functions. Thus, its structure of the tree is significantly more flexible.

In looking forward, you realize that bigger trees are easily constructed. The simple mechanics of binomial trees are preserved, the intuition is still straightforward, and the computations are only marginally more involved than the ones for a standard binomial tree of equal size. Moreover, you note that instead of only using European and American options you can also calibrate the tree to exotic options as long as you can evaluate them on a binomial tree altogether. Also, you make a 
note about talking to the people in fixed income and foreign exchange. After all, you are confident that you can adapt your generalized binomial trees to their calibration problems as well.

One long thought you give to the elegance of the tree. All the fitting and tweaking is done and the tree still guarantees that there are no arbitrage violations. Of course, the secret lies with the weight function but you are still a little bit amazed of how well it works. And also, you did not need any interpolation or extrapolation routine across time and striking prices to come up with hypothetical options as opposed to Derman and Kani (1993) or Dupire (1993). At this point, you understand that in choosing a piecewise linear weight function, you match one option by each kink in the weight function and the connecting segments are a reasonable way to give structure to the remaining tree.

After taking a deep breath you call your client and even get him on the phone. The call would be cost .3769 plus commissions and fees, you tell him. He replies that he will think about it some more. "Great", you think as you shut down the computer and leave for the night. But on your way out you already marvel at the beauty of generalized binomial trees. 


\section{Appendix: Proof of 3-Step Solution Technique with Nodal Probabilities}

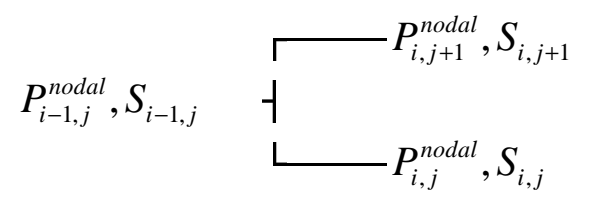

Given the nodal probabilities and stock prices at time i, you can solve for the nodal probability and stock price at the preceding node in three steps:

Step One:

$$
P_{i-1, j}^{\text {nodal }}=\left(1-w_{i, j}\right) P_{i, j}^{\text {nodal }}+w_{i, j+1} P_{i, j+1}^{\text {nodal }}
$$

Step Two:

$$
p_{i-1, j}=w_{i, j+1} \frac{P_{i, j+1}^{\text {nodal }}}{P_{i-1, j}^{\text {nodal }}}=p
$$

Step Three:

$$
S_{i-1, j}=\left[\left(1-p_{i-1, j}\right) S_{i, j}+p_{i-1, j} S_{i, j+1}\right] /(r / \delta)
$$

where: $w_{i, j}=\mathrm{j} / \mathrm{i} \quad$ is the fraction of nodal probability which is going down from a subsequent node to its preceding lower node

$$
\begin{aligned}
& \text { Proof of Step One: } \quad P_{i-1, j}^{\text {nodal }}=\left(\begin{array}{c}
i-1 \\
j
\end{array}\right) P_{i-1, j}^{\text {path }}=\left(\begin{array}{c}
i-1 \\
j
\end{array}\right)\left(P_{i, j}^{\text {path }}+P_{i, j+1}^{\text {path }}\right) \\
& \Leftrightarrow \quad P_{i-1, j}^{\text {nodal }}=\left(\begin{array}{c}
i-1 \\
j
\end{array}\right)\left(\frac{P_{i, j}^{\text {nodal }}}{\left(\begin{array}{c}
i \\
j
\end{array}\right)}+\frac{P_{i, j+1}^{\text {nodal }}}{\left(\begin{array}{c}
i \\
j+1
\end{array}\right)}\right)=\frac{\left(\begin{array}{c}
i-1 \\
j
\end{array}\right)}{\left(\begin{array}{c}
i \\
j
\end{array}\right)} P_{i, j}^{\text {nodal }}+\frac{\left(\begin{array}{c}
i-1 \\
j
\end{array}\right)}{\left(\begin{array}{c}
i \\
j+1
\end{array}\right)} P_{i, j+1}^{\text {nodal }} \\
& \Leftrightarrow \quad P_{i-1, j}^{\text {nodal }}=\frac{\frac{(i-1) !}{j !(i-1-j) !}}{\frac{i !}{j !(i-j) !}} P_{i, j}^{\text {nodal }}+\frac{\frac{(i-1) !}{j !(i-1-j) !}}{\frac{i !}{(j+1) !(i-j-1) !}} P_{i, j+1}^{\text {nodal }}=\frac{i-j}{i} P_{i, j}^{\text {nodal }}+\frac{j+1}{i} P_{i, j+1}^{\text {nodal }} \\
& \Leftrightarrow \quad P_{i-1, j}^{\text {nodal }}=\left(1-\frac{j}{i}\right) P_{i, j}^{\text {nodal }}+\left(\frac{j+1}{i}\right) P_{i, j+1}^{\text {nodal }} \\
& \Leftrightarrow \quad P_{i-1, j}^{\text {nodal }}=\left(1-w_{i, j}\right) P_{i, j}^{\text {nodal }}+w_{i, j+1} P_{i, j+1}^{\text {nodal }}
\end{aligned}
$$

Proof of Step Two: $\quad p_{i-1, j}=w_{i, j+1} \frac{P_{i, j+1}^{\text {nodal }}}{P_{i-1, j}^{\text {nodal }}}=w_{i, j+1} \frac{\left(\begin{array}{c}i \\ j+1\end{array}\right) P_{i, j+1}^{\text {path }}}{\left(\begin{array}{c}i-1 \\ j\end{array}\right) P_{i-1, j}^{\text {path }}}=\frac{w_{i, j+1}}{\frac{j+1}{i}} p=p$ 


\section{References}

Breeden, Douglas, and Robert Litzenberger, 1978, Prices of state-contingent claims implicit in options prices, Journal of Business 51, 621-651.

Cox, John C., Stephen A. Ross, and Mark Rubinstein, 1979, Option pricing: a simplified approach, Journal of Financial Economics 7, 229-263.

Derman, Emanuel, and Iraj Kani, 1994, Riding on a smile, RISK 7, No. 2, 32-39.

Dupire, Bruno, 1994, Pricing with a smile, RISK 7, No. 1, 18-20.

Jackwerth, Jens Carsten, and Mark Rubinstein, 1996, Recovering probability distributions from option prices, Journal of Finance 51, 1611-1631.

Lagnado, Ron, and Stanley Osher, 1996, A technique for calibrating derivative security pricing models: numerical solutions of an inverse problem, working paper, CATS software and University of California at Los Angeles.

Rubinstein, Mark, 1994, Implied binomial trees, Journal of Finance 49, 771-818. 